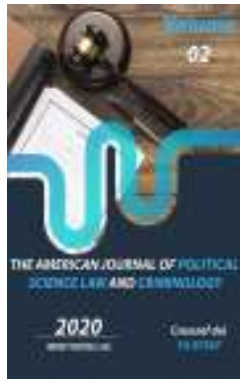

Journal Website: http://usajournalshub.c om/index,php/tajpslc

Copyright: Original content from this work may be used under the terms of the creative commons attributes 4.0 licence.

\section{Some Comments On The Causes And Conditions Of The Offenses}

\author{
Mubarak Akmaldjanovna Usmanova \\ Doctor In Law (DSc), Professor At The Department Of "Sectoral Legal Sciences" Of Military- \\ Technical Institute Of The National Guard Of The Republic Of Uzbekistan \\ Mukaddaskhon Tursunovna Akhmedova \\ Doctor In Law (DSc), Assistant Professor At The Department Of "Sectoral Legal Sciences" Of \\ Military-Technical Institute Of The National Guard Of The Republic Of Uzbekistan
}

\title{
ABSTRACT
}

The article discusses the causes and conditions of the offenses and the consequences of them committed by minors, women and other citizens. Besides, in the research it was also noted that young people should be involved in various activities aimed at productive leisure, raising their legal awareness and culture.

\section{KEYWORDS}

Offense, crime, juveniles, women, rights and freedoms, alcoholism, drug addiction, legal consciousness, legal culture, upbringing.

\section{INTRODUCTION}

In recent years, the bodies and institutions responsible for the harmonious development of minors in our country, the prevention of delinquency and crime, the strengthening of the legal framework for the protection of the rights and interests of minors, the prevention of juvenile delinquency and delinquency attention is being paid. Identifying the causes of violations and the conditions that allow them, their elimination is one of the most pressing issues facing law enforcement agencies and the general public. As a result of delinquency and crime in our society, the rights and freedoms of man and citizens are violated. Therefore, as a result of large-scale work carried out in the country in this direction, positive results have been achieved in some regions and territories. However, this still 
requires us to fight them on a regular basis. Indeed, when we look at the causes of crime, we are convinced that in most cases it is young people, minors with gaps in their upbringing, women in financial difficulties, as well as children from high-income families.

\section{METHODS}

The President of the Republic of Uzbekistan Sh.M.Mirziyoyev instructed to develop a "Road Map", which includes specific measures to prevent delinquency and crime in the districts, based on the specifics of each region. As part of these measures, we can see the following:

First, the introduction of clear evaluation criteria that take into account the effectiveness of crime prevention, including the dynamics of crime, the frequency of their occurrence, public opinion, the satisfaction of citizens with the results of preventive work and the level of cooperation with the population;

Second, to ensure that address sectoral specialization, regional and other specific features are taken into account in the development and implementation of interdepartmental crime prevention programs;

Third, to conduct comprehensive scientific and practical research on crime prevention, to introduce modern methods of preventive work;

Fourth, to develop a system of measures to provide legal, social, psychological, medical, pedagogical and other assistance to victims of offenses and persons with non-social behavior, prone to or have committed offenses;

Fifth, improve the mechanisms for involving citizens and public organizations in crime prevention, including through financial and other incentives [1].

\section{RESULTS AND DISCUSSIONS}

The concept of "Safe Zone" and "Safe City" put forward by the President of the Republic of Uzbekistan on the prevention, combating and identification of offenses and crimes is a clear evidence of our opinion. One thing we can say from the essence of this concept is that not only in every region, but also in families, the preservation of peace and a healthy environment should be the main task of each of us in our daily activities. From time immemorial, we all know that the family is a sacred place, in which the children growing up are the future of society and the state. The Uzbek people, in particular, have always been distinguished from other nations by their goodness, kindness and humane qualities. According to the sources, for many centuries, all thinkers of mankind have been engaged in studying and eliminating the cause of crime in society. Scholars of jurisprudence in Central Asia and ancient Greece sought to study and explain the social factors that affected each person who committed a crime. In particular, Abu Nasr al-Farabi, in his book "City of Noble People", noted that the human being is not born a criminal, but the motives for the violation of his rights are the result of negative vices in society. According to the Greek philosopher Euclid, "a wise legislator takes the necessary measures to prevent crime, rather than being forced to impose punishment for a crime"[2, p.19]. Article 3 of the Law of the Republic of Uzbekistan "On crime prevention" states that "an offense is an illegal act punishable by administrative or criminal liability". The offense is not a person's way of thinking, but his actions, his behavior. Such behavior, on the other hand, manifests itself in the form of an unlawful act or omission. The socially dangerous intention of the offender is reflected only in his actions. The German philosopher Hegel, in his Philosophy of Law, put forward the idea that people should be 
held accountable for their actions, not for their beliefs, intentions [3, p.141]. Resolution of the President of the Republic of Uzbekistan No. PR-4075 of 24 December, 2018 "On Additional Measures to Improve the Effectiveness of Public Safety" and a number of recommendations were developed to ensure the implementation of the Roadmap approved by this resolution. There are various theoretical views in a number of literatures on the causes and conditions that lead to delinquency. Knowing the law of the interdependence of cause and effect, the inextricable link with the conditions, allows us to make an in-depth scientific and theoretical analysis of the offense. This is because it is natural for a certain condition to exist in the origin of the cause.

Consequently, cause and effect cannot be considered in isolation. The cause of the offense is the individual's desire to satisfy his or her own interests, dreams, feelings, in an unlawful way. The causes and conditions of the offense are a reality that causes negative situations in the life of the state and criminal consequences related to a particular socioeconomic formation.

The main conditions of crime in modern Uzbekistan are followings:

1. Difficulties and contradictions in the transition to market relations.

2. Insufficient legal awareness of citizens, level of culture and lack of desire to consciously comply with the law.

3. Alcoholism and drug addiction are the factors that lead to the destruction of the genetic fund of the people.

4. Imperfection of legislation. One of the important tasks of any legislative system is to prevent actions that are harmful to the individual or society as a whole
5. Insufficient efficiency of law enforcement agencies [4, p.301]. There are two situations in which violations occur:

1. Pre-formed social mental states;

1. Circumstances that affect the occurrence of the offense and lead to criminal consequences and increase the crime rate $[5, \mathrm{p} .78]$.It is well known that in the history of each state, reforms have been carried out in specific social, economic, political and cultural areas in the interests of society and its members. Each of the reforms in this area has its own goals and interests. Indeed, ensuring that all reforms in any direction reach their ultimate goal requires reliance on the achievements of science and technology. In analyzing the causes and conditions of rights related to economic reforms, we must take into account the following three situations: First, an analysis of the causes of social conflict; Second, to identify quantitative indicators of offenses and the circumstances that lead to criminogenic cases; Third, to take into account the main characteristics of the subjects of crime.

- In studying the causes of juvenile delinquency and the conditions that allow it, the factors that lead to delinquency can be divided into three groups: socioeconomic, spiritual, organizational and managerial. Agreeing with Professor M.Rustambaev, we can divide the causes and conditions of juvenile delinquency into the following groups:

- Dissemination of videos promoting popular culture;

- Internet propaganda of all kinds of quarrels and fights in public places;

- material shortages;

- Dissolution of the parental marriage, the parent is not real, the parent lives separately; 
- Wrong methods of child rearing: neglect, cruelty, rudeness, discrimination, insult and exploitation;

- The child's opinion is not taken into account by the parents [6, p.17].

1. Another of the main reasons for juvenile delinquency is the inherent nature of the neglect of moral and legal values, the strong desire to access the material resources necessary for entertainment [7, p.26]. Today, it is appropriate to mention some women who commit various offenses and crimes without using the freedom of women and the wide range of conditions created for them. The analysis of current socio-economic processes shows that the main causes of women's crime are:

1. Their active participation in social production;

2. Decreased social control in various segments of society;

3. Disturbances and conflicts between people in society are cases of mutual hostility;

4. The growth of alcoholism, drug addiction, prostitution, homelessness and robbery, which are contrary to the way of life of the society. The increasing participation of women in the division of labor makes them the main breadwinner of the family, which is why sometimes women engaged in commercial activities provide financial support to the family even if they are husbands.

As noted by President Sh.M.Mirziyoyev, "Attention to women should always be at the center of all our efforts, it should be the duty of all of us. Focusing on the family is actually about ourselves"[8]. In addition, in his speech on the occasion of the 27th anniversary of the Constitution of the Republic of Uzbekistan, President of the Republic of Uzbekistan
Sh.M.Mirziyoyev said: A new step in this direction was the reorganization, the provision of additional powers and opportunities, and the creation of the necessary conditions for their full functioning. In 2019, in accordance with Article 46 of the Constitution, the laws "On guarantees of equal rights and opportunities for women and men" and "On protection of women from oppression and violence" were adopted. I think that parliamentary and public control is needed in the consistent implementation of these laws. In the future, the protection of motherhood and childhood, the solution of social problems of women has been in the focus of our state. Recently, many of our women are rising to responsible leadership positions in public and social administration, economics, finance and banking, education, taxation, culture and other areas [9]. Domestic offenses are characterized by specific causes and circumstances. It can be seen that such crimes are mainly caused by people addicted to alcohol and drugs. It is known that a person's propensity to drink causes such defects in his personality as lack of culture, limitation of spiritual qualities, extreme shallowness of needs. In this regard, material deprivation in some individuals encourages them to find and drink with a group of individuals, of course, many of these cases eventually lead to fights and crime. Ensuring the stability of the population, activating the involvement of women and youth in socially useful activities, meaningful organization of leisure time of minors, increasing family incomes, creating honest and prosperous living conditions will serve as a factor in crime prevention. In this regard, the servicemen of the National Guard of the Republic of Uzbekistan are also carrying out a number of practical measures to prevent, combat and identify the causes of offenses and crimes against public order in our country. In particular, it should be noted that professors 
and cadets working at the Military Technical Institute are involved in this task. An example of this is the work done in this regard in the Ferghana Valley and Almazar district of Tashkent from February to December 2019. In particular, the fact that the cadets of the Institute are conscientiously patrolling in Almazar district, actively participating in a number of events aimed at protecting the welfare of our people and protecting the rights and freedoms of citizens is a clear proof of our opinion.

\section{CONCLUSION}

As a future serviceman of the National Guard, our main task is to work tirelessly for the early prevention of delinquency and crime, to explain to the population the rule of law and to live by the law, to treat it with respect serving to cultivate consciousness and culture. Therefore, we must contribute to the constant public awareness and advocacy of the causes and consequences of the offenses, the high level of activities within the concept of familyneighborhood-school. To do this, first of all, we must actively participate in the employment of the unemployed; Second, to express our attitude to the conditions created for the professional development of the youth of the republic and to support its active position; Thirdly, it is expedient to prepare a series of programs and broadcasts about the talented young people and exemplary families, who are achieving success today and contributing to the development of our country.

\section{REFERENCES}

1. Measures to further improve the system of crime prevention and fight against crime // March 27, 2017.
2. Criminology. Textbook. -Tashkent: Academy, 2007. - p.19.

3. Hegel G. Philosophy of Law - Moscow, 1990.

4. Saidov A., Tadjixonov U. Theory of State and Law: Two volumes. Volume 2 Theory of law. - T .: Akademiya, 2001. - Б. 301.

5. Criminology. Textbook. -Tashkent: Academy, 2007.-p.78.

6. D.J. Suyunova, M.A. Usmanova. Regional methodology for the prevention of juvenile delinquency / Textbook, Tashkent, 2019. p.17.

7. Eshmuhammad Kadyrov. Issues of prevention of youth crime. -Tashkent: Nishon Noshir, 2017. -p.26.

8. Commentary to the Decree of the President of the Republic of Uzbekistan "On measures to radically improve the activities in the field of support of women and strengthening the institution of the family" // Khalk suzi 3 February, 2018.

9. The report of the President of the Republic of Uzbekistan Sh.M.Mirziyoyev on the occasion of the 27th anniversary of the adoption of the Constitution of the Republic of Uzbekistan "The Constitution and the rule of law is the most important criterion of a democratic state and civil society" // Khalk suzi 9 December. 